\title{
Brasil Foods: a fusão entre Perdigão e Sadia
}

\author{
Armando Dalla Costa* \\ Elson Rodrigo de Souza-Santos ${ }^{* *}$
}

\begin{abstract}
RESUMO - Este trabalho aborda a formação da Brasil Foods, uma gigante do setor de alimentos formada pela fusão das duas líderes do setor: Sadia e Perdigão. Os aspectos abordados são três. O primeiro consiste no histórico de cada firma e suas estratégias, dentro do ambiente de grande rivalidade entre si. A segunda aborda as motivações e o processo de fusão. Por fim, analisar os impactos da formação de uma empresa desse porte sobre a concorrência e a importância estratégica para o Brasil.
\end{abstract}

Palavras-chave: Perdigão. Sadia. Brasil Foods. Fusão.

\section{INTRODUÇÃO}

No dia 19 de maio de 2009, foi anunciada oficialmente a criação de uma das maiores empresas do ramo de alimentos do Brasil e do mundo denominada Brasil Foods S. A. - BRF, originada da fusão entre a Sadia e Perdigão (SADIA, 2009). Essa fusão trouxe à tona uma série de questões, especialmente em relação à preservação da concorrência nesse mercado e o significado estratégico para o Brasil ao ter uma das maiores multinacionais de alimentos.

A ameaça à concorrência é sintetizada pelo fato das duas companhias compartilharem a liderança em vários segmentos de produtos, constituindo a capacidade de impor preços. Essa visão apoia a argumentação de determinados especialistas e órgãos de defesa do consumidor de que a Brasil Foods reduziria a competição e elevaria os preços de alimentos (FOLHA ONLINE, 2009), opinião compartilhada pelo presidente da Nestlé, Ivan Zurita (G1, 2009). Nessa linha de pensamento, a fusão deveria ser vetada pelo Conselho Administrativo de Defesa Econômica (CADE). Entretanto, a contra-argumentação trata de ressaltar que a natureza do mercado em relação aos competidores e produtos dificulta a capacidade de impor preços elevados. Esta tese foi levantada pelo presidente do conselho de administração da Sadia, Luiz Fernando Furlan, de que a Brasil Foods não colocará em risco a

\footnotetext{
* Pós Doutor pela Université de Picardie Jules Verne, Amiens, França e Doutor pela Université de Paris III (Sorbonne Nouvelle). Professor do Departamento de Economia e no Programa de Pós-Graduação em Desenvolvimento Econômico da UFPR. Coordenador do Núcleo de Pesquisa em Economia Empresarial (www.empresas.ufpr.br). Endereço eletrônico: ajdcosta@ufpr.br.

** Mestrando do Programa de Pós-Graduação em Desenvolvimento Econômico da Universidade Federal do Paraná. Endereço eletrônico: elson129@gmail.com.
} 
fidelidade do consumidor elevando preços devido à competição, mas, ao contrário "trará melhores benefícios de qualidade e também de preço" (G1, 2009c).

De outra perspectiva, a BRF significa que duas gigantes do setor se uniram para ter maior robustez frente às tentativas de compra por parte de empresas estrangeiras e no sentido de fortalecer a competitividade no mercado nacional e internacional (SADIA, 2009b). Assim, a BRF sintetiza a necessidade da criação de multinacionais brasileiras para elevar a integração e fortalecimento da economia do país frente à economia mundial. Por isso o presidente do Banco Nacional de Desenvolvimento Econômico e Social (BNDES), Luciano Coutinho, pretende dar suporte a BRF e justifica com a declaração de que a empresa "pode agregar muitas sinergias na exportação e na presença brasileira como grande empresa nacional, ocupando posição importante no mercado" (FOLHA ONLINE, 2009c).

O trabalho está dividido em três partes. A primeira apresenta um breve histórico da Perdigão e Sadia. A segunda trata das motivações e o processo de fusão. Por último, são exploradas as implicações sobre a concorrência e a importância da BRF como grande multinacional brasileira.

\section{BREVE HISTÓRICO DA PERDIGÃO E SADIA}

Ambas as empresas tiveram origem há mais de 60 anos no oeste catarinense. A Sadia foi fundada por Attilio Fontana em 7 de junho de 1944, na cidade de Concórdia, a partir da aquisição de um frigorífico em dificuldades denominado S. A. Indústria e Comércio Concórdia, posteriormente renomeado como Sadia, nome composto a partir das iniciais SA de "Sociedade Anônima" e das três últimas letras da palavra "ConcórDIA" e que virou marca registrada em 1947, tendo as famílias Fontana e Furlan à sua frente (SADIA, 2009c). A Perdigão foi fundada pelas famílias Brandalise e Ponzoni em 1934, na cidade de Videira, como Ponzoni, Brandalise e Cia, e permaneceu sob a administração da família Brandalise até setembro de 1994, quando o seu controle acionário foi vendido para um consórcio de fundos de pensão brasileiros (PERDIGÃO, 2009).

Atualmente ambas disputam a liderança em vários segmentos alimentícios no mercado interno, são grandes exportadoras e estão entre as maiores companhias de alimentos do mundo (DALLA COSTA; PETIT; BITTTENCOURT, 2008). A Perdigão é sediada em São Paulo (SP), ocupa o terceiro lugar no ranking mundial de abate de aves e está entre as dez maiores em abate de suínos, além de ser uma das principais empresas brasileiras na captação de leite e produção de processados lácteos, massas e pizzas. No mercado interno a Perdigão 
opera com marcas como Perdigão, Chester ${ }^{\circledR}$, Batavo, Elegê, Doriana, Becel (por meio de joint venture com a Unilever) e Turma da Mônica (licenciada). No mercado externo, destacam-se as marcas Perdix, Batavo, Fazenda, Borella e Confidence (PERDIGÃO, 2009b). A Sadia produz e distribui alimentos derivados de carnes suína, bovina, de frango e de peru, além de massas, margarinas e sobremesas, sendo líder brasileira em alimentos industrializados e a sexta maior exportadora do país em 2008. Detém marcas como Qualy, Deline, Excelsior, Rezende e Miss Daisy (SADIA, 2009d). Resumidamente, os dados das duas firmas são comparados abaixo:

QUADRO 1 - COMPARATIVO SADIA E PERDIGÃO (DADOS 2008)

\begin{tabular}{l|r|r}
\hline \multicolumn{1}{c}{ Dados } & Sadia & Perdigão \\
\hline Receita Líquida & $\mathrm{R} \$ 10,7 \mathrm{bi}$ & $\mathrm{R} \$ 11,4 \mathrm{bi}$ \\
Lucro/Prejuízo & $\mathrm{R} \$-2,5 \mathrm{bi}$ & $\mathrm{R} \$ 54 \mathrm{mi}$ \\
Exportação & $\mathrm{R} \$ 5,6 \mathrm{bi}$ & $\mathrm{R} \$ 5,1 \mathrm{bi}$ \\
Funcionários & 60.580 & 59.008 \\
Linha de produtos & 700 & 2.500 \\
Investimento & $\mathrm{R} \$ 1.815 \mathrm{mi}$ & $\mathrm{R} \$ 2.404 \mathrm{mi}$ \\
Faturamento líquido por & & 177 \\
funcionário (em R\$ mil) & 18 & 46,5 \\
Plantas Industriais & 18
\end{tabular}

Fundação

1944 em Concórdia - SC

1934 em Videira - SC

Industrializados congelados, resfriados, massas prontas,

Industrializados congelados de carne, lácteos, massas prontas e

Produtos/Segmentos margarinas e doces vegetais congelados FONTE: Relatórios anuais da Perdigão (2009b, N00026) e Sadia (2009b, N00025). Quadro elaborado pelos autores.

O comparativo entre as empresas apresentado no Quadro 1, traz à tona uma situação interessante de que a Perdigão estava se transformando numa companhia maior do que a Sadia. Segundo Oscar Malvessi, professor de finanças corporativas da FGV-EAESP, em sua coluna na Revista Exame (2009), argumenta que nos últimos 10 anos a Sadia perigosamente se alavancou no mercado financeiro, obtendo lucros ilusórios - $43 \%$ do seu lucro vinha do mercado financeiro - contra uma média de 18\% para as demais empresas de capital aberto. Ao mesmo tempo, Malvessi lembra que a Perdigão crescia e fortalecia a sua marca no setor real, em que no período entre 2000 a 2007, suas vendas cresceram 73\% a mais do que as da Sadia e, em média, 73\% do lucro da Perdigão veio do mercado real sendo mais de 90\% após 2003. Assim, a eclosão da crise em 2008 precipitou a Sadia num enorme prejuízo, mostrado no Quadro 1, de R $\$ 2,5$ bilhões contra um pequeno lucro de $\mathrm{R} \$ 54$ milhões da Perdigão. O resultado reflete a fragilização da Sadia frente às demais empresas, originada de uma estratégia deliberada de alavancagem financeira.

Outro aspecto que influenciou a estratégia da Sadia e Perdigão foi o da natureza dos controladores. A Sadia é uma empresa familiar que apesar de ser de capital aberto, permaneceu sob o comando dos clãs Fontana e Furlan. As famílias, como visto acima, 
preferiam se alavancar no mercado financeiro, considerando-o uma estratégia mais atraente do que correr o risco de perder o controle da companhia (MALVESSI, 2009, p. 30). Apesar da Perdigão ter iniciado as suas atividades como empresa familiar, entre 1990 e 1993, experimentou prejuízos substanciais em razão do aumento de despesas financeiras, baixo investimento em desenvolvimento de produtos, capacidade limitada, bem como divulgação modesta de nossos produtos. O que levou a família Brandalise, em setembro de 1994, a vender o controle acionário para um consórcio de fundos de pensão. A nova administração estruturou e implementou aumentos de capital, programas de modernização, realizou a reestruturação societária, alienou ou liquidou operações comerciais não preponderantes, incrementou a estrutura financeira (PERDIGÃO, 2009). A prioridade dos novos controladores da Perdigão foi fazer a companhia crescer e ganhar solidez, a fim de obter ganhos de longo prazo para satisfazer os seus acionistas.

\section{MOTIVAÇÕES E O PROCESSO DE FUSÃO}

Nos últimos 10 anos Sadia e Perdigão ensaiaram três tentativas de associação. A primeira foi em 1999 que nas palavras de Secches, presidente da Perdigão, "há dez anos nos reuníamos para falar sobre o assunto, mas a conversa não seguiu muito adiante". A segunda foi em 2002 e obteve êxito parcial, onde foi criada a Brazilian Foods (BRF Trading S.A) com atuação voltada para exportação com foco na região conhecida como "Eurásia". A união comercial durou um ano e meio e foi desfeita. A terceira tentativa ocorreu em 2006 e mostrou-se a mais traumática e quase pôs fim a qualquer possibilidade de associação porque foi uma oferta hostil de compra da Perdigão por parte da Sadia, então presidida por Walter Fontana, primo do atual presidente Furlan. O caso arranhou a imagem da Sadia e, recentemente, acabou resultando na instauração do primeiro processo brasileiro por uso de informações privilegiadas na iniciativa privada. "Depois desta última, ficamos com a sensação de que não daria certo mesmo", contou Secches (GAZETA MERCANTIL, 2009). A tentativa de compra da Perdigão por parte da concorrente pode ser atribuída à capacidade de alavancagem financeira da Sadia, mas esta vantagem se transformou num enorme ônus a partir de 2008, como foi visto no item anterior.

Apesar do mal estar causado pela última tentativa, em dezembro de 2008, mais próxima ao Natal, o presidente do Conselho de Administração da Sadia, Luiz Fernando Furlan, atendeu ao telefone e ali foi feito o primeiro contato de uma conversação que duraria mais de cinco meses. Do outro lado da linha, Nildemar Secches, presidente do Conselho de 
Administração da Perdigão, abria o canal para a quarta tentativa de fusão das duas maiores empresas de alimentos do Brasil (GAZETA MERCANTIL, 2009). Segundo a Revista Exame (2009b, p. 19), esses cinco meses de negociações envolveram mais de 60 reuniões e 30 pessoas entre investidores, advogados, banqueiros e representantes de ambos os lados. A Revista Exame também observa que para não levantar suspeitas as reuniões foram feitas em três locais distintos: num quarto de hotel em Osasco, no escritório da Sadia em Higienópolis, e no escritório de advocacia da Perdigão, o Camargo, Bocater, Costa e Silva. Finalmente, em 19 de maio de 2009, foi anunciada a fusão das companhias com a criação da Brasil Foods - BRF.

Os anos de alavancagem financeira da Sadia se transformaram num ônus com a crise de 2008 que foi levada em conta na distribuição das ações da Brasil Foods. Segundo as informações da Revista Exame (2009b, p. 21 e 22), Furlan exigia que a Sadia fosse a controladora da BRF detendo 45\% das ações, justificando a sua posição pelo fato da empresa ter uma receita operacional de $\mathrm{R} \$ 700$ milhões e ser a dona de uma das mais valiosas marcas do país, mesmo com o aperto financeiro e prejuízo de $\mathrm{R} \$ 2,5$ bilhões. De outro lado, os fundos de pensão controladores da Perdigão não aceitaram e ofereceram 19\%. Após duras negociações e argumentações de Secches junto aos fundos de que seria vantajoso dar um percentual maior da BRF para a Sadia, o negócio foi concluído com 68\% para a Perdigão e $32 \%$ para a Sadia. No entanto, os fundos controladores da Perdigão exigiram que a dívida da BRF fosse administrável. Assim, a dívida inicial da nova firma de R 10 bilhões, será em parte abatida pela emissão de ações no valor de $\mathrm{R} \$ 4$ bilhões e que deve ocorrer até o fim de julho de 2009 (G1, 2009e).

Pelo comunicado oficial da Sadia (2009b) entre as vantagens da BRF pode-se destacar que surgiu "uma das maiores companhias de alimentos do mundo, com gestão moderna e modelo de governança corporativa, marcas fortes, diversificação do portfólio e exportações para mais de 110 países". Segundo o Portal Exame (2009b), Furlan da Sadia disse que não há sobreposições entre as fábricas da Sadia e da Perdigão e a preocupação das companhias será ampliar a produção e conquistar novos mercados, especialmente no exterior. Além disso, a Brasil Foods vai ser a maior empregadora privada do país, com mais de 100 mil funcionários. Nildemar Secches da Perdigão observa que as marcas e produtos das duas companhias serão mantidos no mercado. "Vamos ter uma eficiência melhor para atingir novos consumidores a preços acessíveis e boa qualidade", disse. De acordo com a visão da Revista Exame (2009b, p. 20) os pontos fortes das duas empresas são: a Sadia tem uma marca forte que permite cobrar até $15 \%$ a mais nos seus produtos e é pouco dependente dos mercados 
asiático e europeu, ambos afetados pela crise; a Perdigão tem um maior portfólio de produtos, especialmente lácteos e possui uma estrutura de custos mais enxuta.

No Quadro 2 são apresentadas as 10 maiores companhias de alimentos das Américas. Um aspecto intrigante apresentado no quadro é que a maior empresa de alimentos brasileira é o grupo JBS que teve uma estratégia mais acertada e executou o seu plano de expansão adquirindo concorrentes no Brasil e no exterior aproveitando-se do momento propício da economia brasileira e mundial nos períodos anteriores à crise de 2008. De acordo com a Revista Exame (2009b, p. 21), a deterioração financeira da Sadia chegou a tal ponto que Furlan conversou seriamente com duas gigantes do setor, o grupo JBS e a norte-americana Tyson Foods antes de finalizar as negociações com a Perdigão.

\begin{tabular}{|c|c|c|}
\hline Empresa & $\begin{array}{c}\text { Faturamento (bilhões de } \\
\text { US\$ - } 12 \text { meses) }\end{array}$ & País \\
\hline $1^{\circ} \mathrm{ADM}$ & 78,32 & EUA \\
\hline $2^{\circ}$ Kraft Foods & 42,2 & EUA \\
\hline $3^{\circ}$ Tyson Foods & 27,18 & EUA \\
\hline $4^{\circ}$ General Mills & 14,38 & EUA \\
\hline $5^{\circ}$ Sara Lee & 13,43 & EUA \\
\hline $6^{\circ} \mathrm{JBS}$ & 12,98 & Brasil \\
\hline $7^{\circ}$ Kellogg & 12,82 & EUA \\
\hline $8^{\circ}$ Dean Foods & 12,45 & EUA \\
\hline $9^{\circ}$ Heinz & 10,49 & EUA \\
\hline $10^{\circ}$ Brasil Foods & 9,47 & Brasil \\
\hline
\end{tabular}

FONTE: Portal Exame (2009) e site oficial das respectivas empresas.

Oficialmente, o comunicado da Sadia (2009b) define o que será a Brasil Foods, uma das maiores e mais eficientes companhias mundiais de alimentos processados com sede no Brasil, líder no comércio mundial de proteínas animais, elevada escala, capacidade de gestão financeira para expandir-se principalmente no âmbito internacional, alto nível de governança, conquista de novos mercados, estrutura de capital difusa, transparência e liquidez. Além do mais a consultoria Brascan observa que a economia da união será de R \$2,2 bilhões, mas pode chegar ao dobro disso. A analista Denise Messer prevê que a fusão possa gerar um ágio de $20 \%$ no valor de mercado da nova companhia (G1, 2009b).

De acordo com fontes oficiais da Sadia (2009b) o processo de fusão deve seguir as seguintes fases: (i) venda da Concórdia Holding Financeira com o objetivo de segregar atividades da Sadia que não são relacionadas ao ramo de alimentos. A Concórdia Holding Financeira S.A., controladora da Concórdia S.A. E C.V.M.C.C. e do Concórdia Banco S.A., será vendida aos atuais acionistas controladores da Sadia; (ii) A holding controladora da Sadia (HFF) migrará para a BRF através de uma incorporação de ações com a relação de troca: 
0,166247 ação da BRF por 1 ação da HFF e a nova denominação social da Perdigão S.A : BRF - Brasil Foods S.A.; (iii) haverá uma capitalização para a $\mathrm{BRF}^{68}$; e (iv) Os demais acionistas da Sadia migrarão para a BRF através de uma incorporação de ações na relação de troca: 0,132998 ação da BRF por 1 ação dos acionistas minoritários da Sadia.

No processo de formação da BRF não existem vantagens. As empresas terão que superar os obstáculos da integração das duas que vão de filosofia e cultura de operação, até conflitos entre egos. O que pode não só não trazer os resultados esperados como inviabilizar a operação. Em relação à BRF, o primeiro problema que pode surgir é o compartilhamento da presidência do Conselho de Administração. Segundo a Revista Exame (2009b, p 22), Secches tem um perfil de administrador profissional focado na redução de custos e eficiência enquanto Furlan tem um perfil expansionista e empreendedor. É claro que ao invés de um conflito entre as duas visões, pode ocorrer uma complementaridade. Só o tempo dirá qual das duas hipóteses está correta. Atualmente ambos parecem se dar bem e ter um discurso equacionado, como pode ser comprovado na frase de Furlan sobre a copresidência "até agora, eu e Nildemar atuamos como "equilibristas de pratos" para tentar superar a questão emocional. Estamos nos preparando para sermos missionários no sentido de unificar de verdade as duas empresas" (GAZETA MERCANTIL, 2009).

Outro aspecto que pode ser uma potencial fonte de conflitos é que a família Fontana e Furlan deverá ficar com cerca de $12 \%$ das ações da BRF contra $27 \%$ dos fundos de pensão (EXAME, 2009c, p. 29). Como na antiga empresa sempre estiveram no comando, é possível que as famílias Fontana e Furlan queiram ter voz de comando mesmo numa firma onde serão acionistas minoritários.

\section{BRASIL FOODS E SUAS IMPLICAÇÕES}

No item anterior, foram examinadas as motivações e como vai se desenrolar o processo de fusão para a formação da BRF. Nesse tópico são tratados dois aspectos fundamentais da formação dessa nova gigante do setor de alimentos. O primeiro diz respeito aos impactos sobre a concorrência, o segundo trata das considerações estratégicas a respeito da formação de uma empresa multinacional brasileira do porte da Brasil Foods.

\footnotetext{
${ }^{68}$ Está planejada a captação de R \$ 4 bilhões até o mês de julho de 2009.
} 


\subsection{IMPACTO SOBRE A CONCORRENCIA}

Em relação aos impactos sobre a concorrência, existem duas linhas antagônicas. Os contrários que temem que a BRF utilize o seu poder de mercado para elevar o preço dos alimentos e de transacionais que exigem o tratamento equânime em relação à defesa da concorrência. Os favoráveis que incluem na formação da BRF uma sinergia de operações que reduzirá custos e permitirá alimentos a menores preços e maior qualidade para os consumidores, como também a impossibilidade de impor preços ao mercado visto sua natureza e dos demais competidores.

Os contrários à BRF afirmam que o domínio de mercado exercido pela empresa, que pode ser verificado no Quadro 3, pode dar-lhe o poder de impor preços e deixar os alimentos mais caros e com menor qualidade. Segundo a reportagem da Folha Online (2009), essa é a opinião compartilhada pelo Idec (Instituto Brasileiro de Defesa do Consumidor) por meio do seu representante, Marcos Pó, que argumenta que a redução de custos pela fusão não são repassados para o consumidor. Além de citar o caso da Ambev (união das empresas de bebidas Brahma e Antarctica) que usaram o poder de mercado para forçar a retirada de concorrentes menores do mercado. Já Maria Inês Dolci, do Pro Teste (Associação Brasileira de Defesa do Consumidor) argumenta que casos de fusão no Brasil não resultaram em menores preços, mas em menos opções para o consumidor.

QUADRO 3 - PARTICIPAÇÃO DE MERCADO NO BRASIL (EM\%)

\begin{tabular}{l|r|r|r}
\hline \multicolumn{1}{c|}{ Produtos } & Perdigão & Sadia & Brasil Foods \\
\hline Carnes Refrigeradas & 25 & 28 & 53 \\
Carnes Congeladas & 34 & 36 & 70 \\
Massas & 38 & 50 & 88 \\
Pizzas smi-prontas & 34 & 33 & 67 \\
Margarinas & 18 & 30 & 48 \\
\hline
\end{tabular}

FONTE: Portal Exame (2009)

De outro lado, também contrário a fusão, estão as grandes transnacionais em nome do interesse próprio, apesar de fazerem uso de argumentos bem parecidos com as entidades de defesa do consumidor. Nesse caso podem ser citadas as declarações do presidente da Nestlé, Ivan Zurita, ao G1 (2009) de que não pode haver diferenças na avaliação de fusões entre empresas nacionais e internacionais no que tange a concorrência de mercado. Esse questionamento de Zurita tem a ver com o veto do CADE à aquisição da Garoto pela Nestlé há cinco anos, mas como a empresa recorreu, o processo se arrasta sem nenhuma decisão. Ou seja, Zurita gostaria que a Nestlé tivesse o mesmo direito de "dominar" o mercado que a Brasil Foods. 
Entre os defensores do negócio pode ser lembrada a posição de um de seus articuladores e presidente da Sadia, Furlan ao argumentar que as sinergias das empresas vão permitir menores preços e maior qualidade ao consumidor para não por em risco a fidelidade do consumidor $(\mathrm{G} 1,2009 \mathrm{c})$. É difícil acreditar que a BRF repasse os menores custos ao consumidor sem segundas intenções, como também que eleve os preços a ponto de levar outros concorrentes a entrar no mercado. Entretanto dois aspectos podem levar a competição a se manter nos patamares atuais. O primeiro é a operação de grandes multinacionais de alimentos como a Frangosul, comandada pela francesa Doux e a Ceval, comandada pela norte-americana Cargill, mesmo grandes empresas brasileiras como o grupo JBS podem ser impulsionadas a entrar no mercado ou disputar mais ativamente. O segundo aspecto é que pequenos e médios produtores individuais têm certa facilidade em entrar no mercado porque os produtos não contêm alta tecnologia, mesmo pequenos estabelecimentos oferecem produtos substitutos, ou seja, as barreiras de entrada não são intransponíveis.

Antes de aprovar a fusão o CADE irá considerar não apenas a concentração de mercado, mas três aspectos principais citados pela reportagem da G1 (2009d): (i) há possibilidade de, em um prazo de três anos, de outras empresas do mesmo setor entrarem no mercado brasileiro e oferecerem concorrência significativa à empresa em questão; (ii) se existem outras empresas no mercado que tenham condições de elevar a oferta de produtos para fazer rivalidade à nova empresa; e (iii) se a importação de produtos semelhantes e similares aos da nova empresa for fácil e uma alternativa viável em caso de aumento dos preços. Dadas as informações mostradas na argumentação do trabalho, os itens (i) e (ii) estão contemplados e são favoráveis a fusão, mas o item (iii) é um problema porque o Brasil é um dos grandes exportadores de produtos das empresas. Portanto, seria relativamente difícil adquirir esses bens no mercado internacional.

\subsection{ASPECTO ESTRATÉGICO}

A criação da Brasil Foods também envolve um aspecto estratégico fundamental que é a criação de multinacionais brasileiras capazes de competir, fazer frente a outros grandes conglomerados estrangeiros e servir como ponte para uma integração mais altiva do país em relação à economia mundial.

O primeiro e mais aparente aspecto da BRF é a criação da terceira maior exportadora do país, atrás apenas da Petrobras e Vale. Segundo a Revista Exame (2009b, p. 24), um dos objetivos da BRF é elevar a participação no mercado internacional, o que no 
curto prazo deve ter pouco impacto porque as firmas estão iniciando uma articulação para penetrar nesses mercados, especialmente na China e Estados Unidos. Mas na medida em que as estruturas da Sadia e Perdigão se integrarem a tendência é que a BRF terá força suficiente para galgar novos mercados. Posteriormente, além de exportadora, a BRF pode se transformar numa grande investidora estrangeira, capaz até de adquirir companhias no exterior para penetrar em mercados que não tem possibilidade por meio da exportação.

A importância de existirem multinacionais brasileiras do porte da BRF é tão grande que o BNDES através do seu presidente, Luciano Coutinho, de acordo com a Folha Online (2009c) disse a respeito da possibilidade de participar da oferta de ações do BRF que deve ocorrer até julho “... a compreensão é que a empresa resultante precisa fazer uma chamada de capital e poderemos participar, temos interesse. Em que escala e em quais condições, iremos analisar". Mais adiante Coutinho destaca a importância da empresa na integração do Brasil com a economia mundial “... ela pode agregar muitas sinergias na exportação e na presença brasileira como grande empresa nacional, ocupando posição importante no mercado”. Por fim, faz uma ressalva de que as condições mínimas de concorrência devem ser preservadas.

A mensagem de Coutinho contida na reportagem da Folha Online deixa claro que o BNDES pode dar suporte para que Brasil Foods se torne um bom negócio. Isso pode ser identificado como uma estratégia maior do país em criar multinacionais brasileiras, refletindo numa maior competitividade e fortalecimento do Brasil no cenário internacional.

\section{CONSIDERAÇÕES FINAIS}

Esse trabalho abordou a criação da Brasil Foods, originária da fusão entre duas gigantes do ramo de alimentos brasileiro: Perdigão e Sadia. Primeiro trazendo um breve histórico da trajetória e quadro atual das duas companhias. Depois entrando propriamente nas motivações e como se dará o processo de fusão. Finalmente, as implicações, concorrências e estratégias da criação da BRF.

Dentro da construção do artigo duas conclusões podem ser retiradas sobre a Brasil Foods. A primeira é que a companhia tem uma elevada participação no mercado de alimentos brasileiro, porém isso não significa necessariamente que tenha poder de impor preços porque existem concorrentes multinacionais que atuam no mercado e potenciais entrantes que podem ser motivados a agir se a BRF iniciar uma política de aumento de preços. A segunda é que a BRF representa a criação de uma multinacional brasileira que não só é uma das maiores exportadoras do país, mas que pode se transformar numa grande investidora e compradora de 
empresas estrangeiras, em busca de desbravar novos mercados e obter maiores lucros. Estrategicamente isso significa que o Brasil ganha solidez e contribui para uma maior participação na economia mundial como investidor e não apenas receptor de capitais.

\section{REFERÊNCIAS}

DALLA COSTA, A.; PETIT, P.; BITTENCOURT, M.V.L. Innovations, technological economic development: An evolutionay view of the Brazilian poultry and its firms. Anais do III Research Workshop on Institutions and Organisations. São Paulo: USP, IBMEC, FGV-SP. Disponível em http:/ /www.empresas.ufpr.br/publicacoes/artigos.

FOLHA ONLINE (2009). União Sadia-Perdigão pune consumidor, dizem analistas. Disponível em: http://www1.folha.uol.com.br/folha/dinheiro/ult91u565681.shtml Acesso em: 27 mai. 2009.

FOLHA ON-LINE. (2009b). BNDES manifesta interesse de participar da Brasil Foods.

Disponível em: http:/ / tools.folha.com.br/print?site $=$ emcimadahora\&url=http $\% 3 \mathrm{~A} \% 2 \mathrm{~F} \% 2 \mathrm{Fwww1}$.folha.uol. com.br\%2Ffolha\%2Fdinheiro\%2Fult91u568157.shtml Acesso em: 28 mai. 2009.

FOLHA ONLINE. (2009c). A Perdigão e a Sadia fizeram pelo menos cinco tentativas de fusão. Disponível em: http://www1.folha.uol.com.br/folha/dinheiro/ult91u567495.shtml Acesso em: 28 mai. 2009.

G1. (2009). Presidente da Nestlé quer 'regras iguais' para operação Sadia-Perdigão. Disponível em: <http://g1.globo.com/Noticias/Economia_Negocios/0,MRP1159837-9356,00.html> Acesso em: 28 mai. 2009.

G1. (2009b). União de Sadia e Perdigão cria 'gigante' brasileira dos alimentos. Disponível em: http://g1.globo.com/Noticias/Economia_Negocios/0,MRP1125247-9356,00.html Acesso em: 28 mai. 2009.

G1. (2009c). Perdigão e Sadia anunciam 'grande multinacional' do setor de alimentos. Disponível em: http://g1.globo.com/Noticias/Economia_Negocios/0,MUL11594659356,00-

PERDIGAO+E+SADIA+ANUNCIAM+CRIACAO+DA+BRASIL+FOODS.html Acesso em: 28 mai. 2009.

G1. (2009d). Conheça os passos do Cade para aprovar ou rejeitar a fusão Sadia-Perdigão. Disponível em: http://g1.globo.com/Noticias/Economia_Negocios/0,,MUL11614719356,00-

CONHECA+OS+PASSOS+DO+CADE+PARA+APROVAR+OU+REJEITAR+A+FUS AO+SADIAPERDIGAO.html Acesso em: 28 mai. 2009.

G1. (2009e). Oferta de R \$ 4 bilhões da Brasil Foods deve sair até o fim de julho, diz diretor. Disponível em: http://g1.globo.com/Noticias/Economia_Negocios/0,MRP11602809356,00.html. Acesso em: 28 mai. 2009.

GAZETA MERCANTIL. (2009). Após três tentativas frustradas, Sadia e Perdigão anunciam fusão.

em: http://indexet.gazetamercantil.com.br/arquivo/2009/05/20/378/Apos-tres-tentativasfrustradas,-Sadia-e-Perdigao-anunciam-fusao.html. Acesso em: 28 mai. 2009. 
PERDIGÃO. (2009). Perfil Corporativo e Histórico. Disponível em: http://www.perdigao.com.br/ri/default.html. Acesso em29 mai. 2009.

PERDIGÃO. (2009b). Relatório Anual 2008. Disponível em: http://www.perdigao.com.br/ri/web/arquivos/Relatorio_Anual_2008.pdf. Acesso em: 28 mai. 2009.

PORTAL EXAME. (2009). O impacto de uma eventual fusão entre Sadia e Perdigão. Disponível em: http://portalexame.abril.com.br/negocios/impacto-eventual-fusao-sadiaperdigao-469667.html. Acesso em 28 mai. 2009.

PORTAL EXAME. (2009b). Furlan: oferta de ações da Brasil Foods ocorre até julho. Disponível em: http://portalexame.abril.com.br/ae/financas/furlan-oferta-acoes-brasilfoods-ocorre-julho-391479.shtml. Acesso em: 27 mai. 2009.

REVISTA EXAME. (2009). Onde a Sadia perdeu o jogo: ou por que a perdigão comprou a Sadia - e não o contrário. Revista Exame. São Paulo: Abril, ed. 944, ano 43, n. 10, 3 de junho de 2009, p. 30.

REVISTA EXAME. (2009b). Felizes para sempre?. Revista Exame. São Paulo: Abril, ed. 944, ano 43, n. 10, 3 de junho de 2009, p. 18 - 24.

REVISTA EXAME. (2009c). Uma saga familiar chegando ao fim. Revista Exame. São Paulo: Abril, ed. 944, ano 43, n. 10, 3 de junho de 2009, p. 26 - 29.

SADIA. (2009). Sadia e Perdigão. Disponível em: http://ri.sadia.com.br/ptb/1682/Fato\%20Relevante_19.05.09.pdf. Acesso em: 28 mai. 2009.

SADIA. (2009b). Associação entre Perdigão e Sadia. Disponível em: http://ri.sadia.com.br/ptb/1692/Apresenta\%E7\%E30\%20Investidores_V4_.pdf Acesso em: 28 mai. 2009.

SADIA. (2009c). Anos 40.4 Disponível em: <http://www.sadia.com.br/br/empresa/historico_40.asp> Acesso em: 28 set. 2009.

SADIA. (2009d). Relatório Anual 2008. Disponível em: http://ri.sadia.com.br/ptb/1632/sadia_ra2008.pdf. Acesso em: 28 mai. 2009. 